Buxton, E. W. (1956). J. gen. Microbiol. 15, 133-139

\title{
Heterokaryosis and Parasexual Recombination in Pathogenic Strains of Fusarium oxysporum
}

\author{
By E. W. BUXTON \\ Rothamsted Experimental Station, Harpenden, Hertfordshire
}

\begin{abstract}
SUMMARY: Mutants of Fusarium oxysporum f. pisi (cause of pea wilt), distinguished from the parent types by their different morphology, pathogenicity and nutritional requirements, were obtained by ultraviolet irradiation. Pairs of mutants with different nutritional requirements (auxotrophs) formed balanced heterokaryons on nonsupplemented medium. Most of the auxotrophs were less pathogenic than the wildtypes, whereas heterokaryons between the mutants were not.

Single conidia of a heterokaryon between an auxotroph from race 1 and one from race 2 of Fusarium oxysporum gave a small proportion $\left(3\right.$ in $\left.10^{8}\right)$ of colonies which were able to grow on non-supplemented medium. These three prototrophs were presumably diploid because vegetatively they gave new strains with various combinations of colour, nutritional requirements, actinomycete tolerance and pathogenicity.

The results indicate that, in fusaria, heterokaryosis plays a part in variation of virulence and that Fusarium oxysporum, which has no known sexual stage, has a system similar to the parasexual cycle described by Pontecorvo for certain other Fungi Imperfecti, that permits the segregation and recombination of genetic factors outside the sexual stage.
\end{abstract}

Many plant pathogenic fungi which seem to have no perfect stage nevertheless vary greatly in their pathogenicity. Analyses of laboratory mutants of some Fungi Imperfecti by Pontecorvo, Roper \& Forbes (1953) and by Pontecorvo \& Sermonti (1954) showed how genetical techniques can be applied to imperfect fungi. Heterokaryons (colonies with hyphae containing nuclei of different genetic types) regularly produced rare diploid nuclei, and characters recombined in new ways in the subsequent mitotic divisions. That heterokaryosis could affect the virulence of fungi was shown by Hansen (1938), who worked with Phoma terrestris and Botrytis cinerea.

The present paper describes experiments made to test whether or not heterokaryosis and a system of recombination occur in Fusarium spp. and could explain some of their variability in pathogenicity. $F$. oxysporum $F r$. includes soil-borne pathogens which cause serious diseases of crops such as banana, flax, peas and tomatoes. Buxton (1954) showed that culturally distinct isolates of $\boldsymbol{F}$. oxysporum Fr. f. gladioli Snyder \& Hansen (cause of gladiolus yellows) form heterokaryons on agar media. As usual, when these fungi are exposed to ultraviolet radiation, mutants occur which differ from the parent type and from one another in their requirements for growth factors. Pairs of nutritional mutants (auxotrophs) may be able to form heterokaryons with each other, heterokaryons which can grow on media devoid of the growth factors necessary for mutants themselves.

Auxotrophic mutants, produced by ultraviolet radiation, were used in the 
work described below because morphological features in fusaria are unreliable as genetic markers and are rarely related to differences in pathogenicity, either the plants attacked or the severity of the disease caused. F. oxysporum f. pisi (cause of pea wilt) is suitable for this type of work because it grows quickly in culture and produces many conidia on agar media. Moreover, peas are easy to grow in quantity and disease symptoms appear quickly.

\section{RESULTS}

Production of nutritional and morphological mutants. Three isolates were used, grown from single conidial cultures derived from colonies isolated from diseased peas: Fusarium oxysporum f. pisi race 1 (American isolate from wilted peas); $F$. oxysporum f. pisi race 1, 612 A (English isolate from wilted peas); $F$. oxysporum f. pisi race 2 (American isolate from 'near-wilted' peas).

Conidia were irradiated with ultraviolet light from a Hanovia XII medium pressure lamp, $95 \%$ of the irradiation being of wavelength $2537 \mathrm{~A}$., giving $173 \mu \mathrm{W} . / \mathrm{cm} .^{2}$ at $40 \mathrm{~cm}$. distance. Specific nutritional requirements, detected by the usual techniques (Pontecorvo, 1953), are shown in Table 1. Before auxotrophs produced in this way were used in experiments, cultures were established from single conidia.

Table 1. Auxotrophs and morphological mutants obtained by ultraviolet irradiation of Fusarium oxysporum $f$. pisi

Mutants obtained after screening tests

\begin{tabular}{|c|c|c|c|c|c|c|c|}
\hline \multirow[b]{3}{*}{ Strain irradiated } & \multirow{3}{*}{$\begin{array}{c}\text { Conidia irradiated } \\
\text { (1000/dish) to give } \\
10 \% \text { survival }\end{array}$} & \multirow{3}{*}{$\begin{array}{l}\text { Colonies } \\
\text { isolated } \\
\text { (from 10\% } \\
\text { survival } \\
\text { level) }\end{array}$} & \multicolumn{2}{|c|}{ Nutritional } & \multicolumn{3}{|c|}{ Morphological } \\
\hline & & & \multirow{2}{*}{$\begin{array}{l}\text { Amino } \\
\text { acid } \\
\text { requirers }\end{array}$} & \multirow{2}{*}{$\begin{array}{l}\text { Nucleic } \\
\text { acid } \\
\text { requirers }\end{array}$} & \multirow{2}{*}{\multicolumn{3}{|c|}{$\begin{array}{l}\text { Semi- } \\
\text { dwarfs } \\
\text { and } \\
\text { slow- } \\
\text { growers }\end{array}$}} \\
\hline & & & & & & & \\
\hline$m$ f. $p i s i$ race 1 & 45,000 & 1109 & 18 & $\mathbf{5}$ & 4 & 0 & 10 \\
\hline$u m$ f. pisi race $1(612 A)$ & $\mathbf{3 2 , 0 0 0}$ & 726 & 12 & 4 & 4 & $\mathbf{2}$ & 17 \\
\hline$u m$ f. pisi race 2 & 8,000 & 284 & 1 & 1 & $\mathbf{0}$ & $\mathbf{0}$ & 1 \\
\hline & 85,000 & 2119 & 31 & 10 & 8 & 2 & 28 \\
\hline
\end{tabular}

Formation of heterokaryons in culture. Six of the auxotrophs were selected, and attempts were made to form balanced heterokaryons between pairs of them by streaking the mixed spores on a minimal medium (Pontecorvo, 1949) on which either alone has a lag period and then shows limited growth. Heterokaryons showed within a few days as fans of faster-growing mycelium. All pairs of the mutants of Fusarium oxysporum $\mathrm{f}$. pisi race 1 (American isolate) and $F$. oxysporum f. pisi race 1, 612 A, formed balanced heterokaryons and had growth rates approximately equal to that of the wild-types.

Table 2 shows the types of the mutants used in the experiments. In addition, 21 dwarf mutants, with colour differences but no detectable nutritional deficiencies, readily formed heterokaryons whose growth rates were greater than those of the dwarfs, but only half those of the wild-types. 
Table 2. Origin and type of Fusarium mutants used in the inoculation experiments

\begin{tabular}{|c|c|c|c|}
\hline \multirow{3}{*}{$\begin{array}{l}\text { Code no. } \\
\text { C25 }\end{array}$} & \multirow[b]{2}{*}{ Origin } & \multicolumn{2}{|c|}{ In vitro characteristics } \\
\hline & & $\begin{array}{l}\text { Nutritional } \\
\text { requirement }\end{array}$ & $\begin{array}{l}\text { Morphological } \\
\text { appearance }\end{array}$ \\
\hline & $\begin{array}{l}F \text {. oxysporum f. pisi race } 1,612 \mathrm{~A} \\
\text { (English isolate) }\end{array}$ & Methionine & Bushy \\
\hline K27 & $\begin{array}{l}\text { F. oxysporum f. pisi race 1, 612A } \\
\text { (English isolate) }\end{array}$ & Yeast nucleic acid & Dendritic \\
\hline $\mathrm{H} 20$ & $\begin{array}{l}\text { F. oxysporum f. pisi race } 1 \\
\text { (American isolate) }\end{array}$ & Asparagine & Normal \\
\hline H32 & $\begin{array}{l}\text { F. oxysporum f. pisi race } 1 \\
\text { (American isolate) }\end{array}$ & Arginine & Normal \\
\hline
\end{tabular}

Inoculation experiments. The virulence of auxotrophs was compared with that of balanced heterokaryons formed between them. Pea seedlings of the variety Onward (susceptible to wilt) were raised in boxes of unsterilized John Innes compost, and later inoculated as described by Buxton (1955). The pots of inoculated plants were stood in peat maintained at $21^{\circ}$ and illuminated (fluorescent $40 \mathrm{~W}$. tubes) with 340 f.c. at soil level for $3 \mathrm{hr}$. each day at dusk. Disease incidence and disease rating (the ratio of wilted leaves to total leaves per plant, expressed as a percentage) were recorded at weekly intervals.

Table 3. Disease ratings of peas inoculated with nutritional mutants, heterokaryons and wild-types of Fusarium oxysporum $f$. pisi

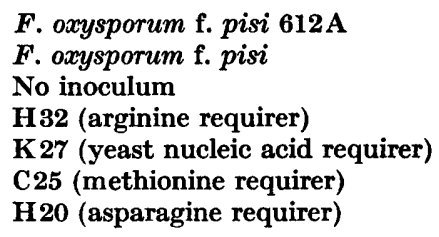

$\begin{array}{cc}\text { Single strains } & \text { Heterokaryons } \\ \begin{array}{c}100 \cdot 0 \\ 100 \cdot 0\end{array} & - \\ \left.\begin{array}{c}62 \cdot 5 \\ 40 \cdot 0 \\ 47 \cdot 5 \\ 83 \cdot 7\end{array}\right\} & - \\ & -\end{array}$

The figures are the means of the results of six identical experiments, seventy-two replicates in all, and are significant at $0 \cdot 1 \%$ level.

The two auxotrophs of Fusarium oxysporum $\mathrm{f}$. pisi race 1, 612A, tested were less than half as virulent as the wild-type or heterokaryon. The two autotrophs of $F$. oxysporum $\mathrm{f}$. pisi race 1 (American isolate) tested were also less virulent than their parent type. When the heterokaryons were used as inoculum, their virulences were equal to those of the wild-types, a stimulus probably caused by complementary gene action analogous to that restoring growth rate on minimal medium in vitro.

Nutritional deficiencies may decrease the pathogenicity of mutants by preventing either penetration of the host-plant root or growth within it. Plants inoculated with mutants C25 (methionineless, bushy) or K27 (yeast nucleic acid-less, dendritic) were therefore treated with a solution of the required nutrient 4 days after transplanting. The nutrients were either added to the soil near the roots or directly injected into the stem base $2 \mathrm{~cm}$. above soil 
level. After adding the nutrients to the soil, the pathogenicity of both mutants was restored to about $80 \%$ of that of the wild-type, whereas injection into the stem restored the pathogenicity to only $60 \%$ of that of the wild-type.

To find whether the mutant, wild-type or heterokaryon had been modified during passage through the plants, pieces of the stele and cortex of stem bases and roots from inoculated plants were plated on agar media. From plants inoculated with either mutants or heterokaryons the fungus used as inoculum was recovered and identified. Most of the heterokaryons retained their original form, as shown by culturing single conidia from them, but a few hyphae that grew from plants inoculated with heterokaryons contained only one or other of the mutant-type nuclei from which the heterokaryon was originally synthesized.

Segregation and recombination between physiologic races. Pontecorvo (1954) emphasized that heterokaryosis alone cannot give rise to strains with new hereditary constitutions. The experiments described above suggest that, as expected on genetical theory, increased virulence can arise as a phenotypic result of heterokaryosis between two mildly virulent strains. It seemed important to find whether or not, in addition, any system of recombination between physiologic races occurred in Fusarium oxysporum.

To investigate this possibility, conidia of single mutants of physiologic races 1 and 2 were re-exposed to ultraviolet radiation to obtain multiple mutants of each race. Twelve multiple mutants, requiring specific amino-acids, were tested for pathogenicity and one from each race finally selected because it retained its wild-type pathogenicity. These two were further characterized by their actinomycete tolerance (Buxton \& Richards, 1955) and by their colour on modified Czapek-Dox agar (less $\mathrm{NaNO}_{3}$ ) when incubated in darkness at $25^{\circ}$. Balanced heterokaryons were formed between them and single conidial suspensions were spread on a minimal agar medium to detect possible diploids (Roper, 1952; Pontecorvo et al. 1953). From $10^{8}$ conidia, three proved to be prototrophs on the minimal medium and were subcultured as single conidia to minimal agar slants. When $\mathbf{3 6 0}$ single conidia of these prototrophs were cultured on augmented minimal medium, twelve showed segregation or recombination of the characters of the original heterokaryon (Table 4). The six that differed most from the two original components of the heterokaryon were then tested for their pathogenicity towards three pea varieties that differentiate the three physiologic races of Fusarium oxysporum f. pisi (Schreuder, 1951; Buxton, 1955), to see whether factors determining race specificity could combine in new ways with each other and with other known 'markers'.

Nearly all recombinants retained the white colour of the original component E6/12 on the modified Dox agar. Strains 5 and 6 were prototrophic but no longer red. Actinomycete tolerance, which was lost by the heterokaryon $\mathrm{B28} / 1+\mathrm{E} 6 / 12$, was regained by strains 8 and 11. The pathogenic abilities of the mutants, which were tested in replicated experiments on three different occasions, showed an equally high degree of recombination with the auxotrophic properties. In strain 8 , pathogenicity was lost completely, whereas 
strains 5 and 10 had race 2 type pathogenicity, identical with that of E6/12. Three of the strains (1, 3 and 9) affected var. Delwiche Commando, although only one of them, strain 3, also wilted var. Alaska.

That the prototrophs were probably diploid may be inferred from the fact that they grew like wild-types on minimal agar, and that they subsequently produced segregants and recombinants. Table 4 shows that this occurred both in cultural and in pathogenic properties. Furthermore, spore measurements

Table 4. Nutritional mutants used in the synthesis of heterokaryons, and segregation and recombination in Fusarium oxysporum $f$. pisi races 1 and 2

\begin{tabular}{|c|c|c|c|c|c|c|c|c|c|c|c|c|}
\hline \multirow[b]{3}{*}{ Colonies tested } & & & & & & & & \multirow{3}{*}{$\begin{array}{c}\text { Colour on } \\
\text { modified } \\
\text { Czapek-Dox } \\
\text { agar }\end{array}$} & \multirow{3}{*}{$\begin{array}{l}\text { Actino- } \\
\text { mycete } \\
\text { tolerance }\end{array}$} & \multicolumn{3}{|c|}{$\begin{array}{l}\text { Pathogenicity on pea } \\
\text { varieties }\end{array}$} \\
\hline & \multicolumn{7}{|c|}{$\begin{array}{l}\text { Nutritional 'markers' (as growth responses } \\
\text { on augmented minimal media) }\end{array}$} & & & & & $\begin{array}{c}\text { Del- } \\
\text { wiche }\end{array}$ \\
\hline & Arg. & Asp. & Cyst. & Glut. & Meth. & Pro. & Vit. $B_{1}$ & & & ward & Alaska & mando \\
\hline Race 1 & - & - & - & - & - & - & - & White & + & + & - & - \\
\hline Race 2 & - & - & - & - & - & - & - & Red & - & + & + & - \\
\hline B 28/1 (ex race 1$)$ & - & - & + & - & + & - & $+t$ & Red & - & + & - & - \\
\hline E6/12 (ex race 2) & + & + & - & + & - & + & - & White & + & + & + & - \\
\hline Heterokaryon B $28 / 1+$ E $6 / 12$ & - & - & - & - & - & - & - & Red & - & + & - & - \\
\hline Prototroph B 28/1/E6/12 & - & - & - & - & - & - & - & Red & - & + & + & - \\
\hline \multicolumn{13}{|c|}{ Recombinants and segregants from prototroph: } \\
\hline 1 & - & - & - & - & - & - & - & White & - & \multirow[t]{2}{*}{+} & \multirow{2}{*}{ Not tested } & + \\
\hline 2 & + & - & - & - & + & + & - & Red & - & & & \\
\hline 3 & + & $\mathbf{I}$ & - & - & + & + & $\rightarrow$ & Red & - & + & + & + \\
\hline 4 & - & - & - & - & + & + & - & Red & - & & Not tested & \\
\hline 5 & - & - & - & - & - & - & - & White & - & + & + & - \\
\hline 6 & - & - & - & - & - & - & - & White & - & & Not tested & \\
\hline 7 & + & - & - & - & + & + & - & White & - & & Not tested & \\
\hline 8 & + & - & - & - & + & + & I & White & + & - & - & - \\
\hline 9 & + & - & - & + & + & + & - & White & - & + & - & + \\
\hline 10 & + & I & - & - & + & + & - & White & - & + & + & - \\
\hline 11 & + & - & - & - & + & + & - & White & + & & Not tested & \\
\hline 12 & + & - & - & - & + & + & - & White & - & & Not tested & \\
\hline
\end{tabular}

Arg. $=$ arginine; Asp. $=$ asparagine $;$ Cyst $=$ cystine; Glut. $=$ glutamine; Meth. $=$ methionine; Pro.$=$ proline; Vit. $B_{1}=$ vitamin $B_{1} ;$ $\mathrm{I}=$ inhibition. Cyst., meth. and vit. $\mathrm{B}_{1}$ are all required by $\mathrm{B} 28 / 1$; arg. and asp. are both required by $\mathrm{E} 6 / 12$, but glut. and pro. are alternatives to asparagine.

showed that the diameters of the prototroph microconidia, which are uninucleate (Buxton, 1954), were $1 \cdot 23$ times those of both original mutants, B 28/1 and E6/12. All this suggests that Fusarium oxysporum f. pisi has a system comparable to the parasexual system described in Aspergillus niger (Pontecorvo et al. 1953) and in Penicillium chrysogenum (Pontecorvo \& Sermonti, 1954). This system may explain many, but by no means all, of the morphological changes fusaria undergo in culture and of changes in pathogenicity and saphrophytic ability of wild-types. A genetic analysis of pathogenicity in $F$. oxysporum, where no perfect stage is known, might be possible by the methods recently outlined by Pontecorvo \& Kafer (1954).

\section{DISCUSSION}

Fusaria vary greatly in morphology and in pathogenicity, and many workers have attempted to establish a relationship between a particular cultural type and a defined pathogenicity. Borlaug (1945) showed that several 'biotypes', differing in pathogenicity, occurred in his isolates of Fusarium lini. Cormack 
(1951) recorded variability in virulence of isolates of $F$. avenaceum and $F$. arthrosporioides and showed that it was, to a limited extent, related to differences in cultural morphology. Oswald (1949) found that two types of fusaria from cereals with root-rots differed morphologically and in virulence. None of these authors considered how fusaria maintain variability in nature, although Snyder (1933) suggested that heterokaryosis might be important in cultural variation, and Leonian (1930) considered that dissociation in fusaria might be due to an undiscovered process which he called 'amorphous sexualism'.

From the many forms of fusaria in the soil, those are selected which can attack the host plant. The experiments described in this paper suggest how these separate pathogenic units could be combined in heterokaryons to produce units with increased virulence.

The ability of weak pathogens to enhance virulence by forming heterokaryons obviously offers a better chance of survival, for weak parasites would thus be given better opportunity to invade a living host and avoid competition with saprophytic soil organisms. Similarly, any deficiencies that limit saprophytic growth in soil might be overcome by heterokaryons forming between strains with different metabolic capabilities. The advantage endowed by heterokaryosis, however, is limited by the pool of genetic potentialities already existing within particular fusarium populations in the soil. With heterokaryosis alone, no recombination of these characters is possible, and, indeed, the system can only increase the competitive ability of fusaria by bringing together in a common cytoplasm nuclei from two strains which are poorly virulent but for different physiological reasons (Pontecorvo, 1954), and this might result in increase or decrease of parasitic ability. The existence of a parasexual cycle enhances the possibilities of survival of the different physiologic races when only unsuitable host varieties are available for infection. In diploids, heterozygosity could be perpetuated and their potentiality for segregation and recombination would enable new hosts to be invaded or new soil environments to be tolerated. That diploids can give rise to new types of pathogenicity, as shown by the ability of some of these new types to infect var. Delwiche Commando, a differential host for race 3 , does not imply, of course, that race 3 arises in nature from races 1 and 2 .

\section{REFERENCES}

Borlaug, N. E. (1945). Variation and variability of Fusarium lini. Bull. Minn. agric. Exp. Sta. no. 168.

Buxton, E. W. (1954). Heterocaryosis and variability in Fusarium oxysporum f. gladioli (Snyder \& Hansen). J. gen. Microbiol. 10, 71.

Buxton, E. W. (1955). Fusarium diseases of peas. Trans. Brit. mycol. Soc. 38, 309.

Buxton, E. W. \& Richards, M. G. (1955). Pathogenic strains of Fusarium oxysporum Fr. distinguished by their differential tolerance to inhibition by various actinomycetes. J. gen. Microbiol. 13, 99.

Cormack, M. W. (1951). Variation in the cultural characteristics and pathogenicity of Fusarium avenaceum and F. arthrosporioides. Canad. J. Bot. 29, 32.

Hansen, N. H. (1938). The dual phenomenon in Imperfect fungi. Mycologia, 30, 442.

Leonian, L. H. (1930). Attempts to produce 'mixochimaera' in Fusarium moniliforme. Phytopathology, 20, 895. 
Oswald, J. W. (1949). Cultural variation, taxonomy and pathogenicity of Fusarium species associated with cereal root rots. Phytopathology, 39, 359.

Pontecorvo, G. (1949). Auxanographic techniques in biochemical genetics. J. gen. Microbiol. 3, 122.

Ponteconvo, G. (1953). The genetics of Aspergillus nidulans. Advanc. Genet. 5, 141.

Pontecorvo, G. (1954). Mitotic recombination in the genetic systems of filamentous fungi. Proc. IX Intern. Congr. Genet. Part I, p. 192. (Caryologia, vol. suppl. 1954.)

Ponteconvo, G. \& Kafer, E. (1954). Maps of a chromosome region in Aspergillus nidulans based on mitotic and meiotic crossing over. Heredity, 8, 433.

Pontecorvo, G., Roper, J. A. \& Forbes, E. (1953). Genetic recombination without sexual reproduction in Aspergillus niger. J. gen. Microbiol. 8, 198.

Pontecorvo, G. \& Sermonti, G. (1954). Parasexual recombination in Penicillium chrysogenum. J. gen. Microbiol. 11, 94.

Roper, J. A. (1952). Production of heterozygous diploids in filamentous fungi. Experientia, 8, 14.

Schreuder, J. C. (1951). Een onderzoek over de Amerikaanse Vaatziekte van Erwten in Nederland. Tijdschr. PlZiekt. 57, 175.

SNyder, W. C. (1933). Variability in the pea wilt organism, Fusarium orthoceras var. pisi. J. Agric. Res. 47, 65.

(Received 10 January 1956) 